\title{
The Editors' Medal 2008
}

\author{
Dierk Vorwerk · Ziv J. Haskal · Yasuaki Arai
}

Published online: 8 July 2008

(C) Springer Science+Business Media, LLC 2008

As in previous years, the Editorial Board has had the honor of nominating publications from the 2007 volume of the journal for the Editor's Medal. Publications are chosen via a poll of our very responsive Editorial Board and Consultant members, and include original and experimental submissions only.

This year the editors decided not to limit the medal to a single publication, but to award it to two publications, in order to respond to the increasing interest in the journal, as indicated by the increased number of submissions, which reached nearly 500 manuscripts in 2007.

Thus, it is our pleasure to present Dr. Zampakis's [1] and Dr. Stampfl's [2] groups the Editor's Medal for 2008. As always, the award is accompanied by a considerable

donation from our publisher, Springer Science+Business Media, LLC. Congratulations to the winners!

\section{References}

1. Zampakis P, Karnabatidis D, Kalogeropoulou C, Kardamakis DM, Katsanos K, Skouras T, Siablis D (2007) External beam irradiation and restenosis following femoral stenting: long-term results of a prospective randomized study. Cardiovasc Intervent Radiol 30(3):362-369

2. Stampfl S, Stampfl U, Rehnitz C, Schnabel P, Satzl S, Christoph P, Henn C, Thomas F, Kauffmann GW, Richter GM (2007) Experimental evaluation of early and long-term effects of microparticle embolization in two different mini-pig models. Part I: kidney. Cardiovasc Intervent Radiol 30(2):257-267

D. Vorwerk

Department of Radiology, Klinikum Ingolstadt,

Krumenauerstrasse 25, Ingolstadt 85049, Germany

e-mail: dierk.vorwerk@klinikum-ingolstadt.de

\section{Z. J. Haskal ( $\square)$}

Divison of Vascular and Interventional Radiology,

NewYork-Presbyterian Hospital/Columbia Univ. Medical Ctr.,

177 Fort Washington Ave., MHB 4-100 New York, NY, USA

e-mail: zh50@columbia.edu

\section{Y. Arai}

Division of Diagnostic Radiology and Nuclear Medicine,

National Cancer Hospital, 5-1-1 Tsukiji, Chuo-ku,

Tokyo 104-0045, Japan

e-mail: arai-y3111@mvh.biglobe.ne.jp 